\title{
Digital Competence and Capability Frameworks in the Context of Learning, Self-Development and HE Pedagogy
}

\author{
David Biggins \& Debbie Holley \\ Bournemouth University, Centre for Excellence in Learning \\ Talbot Campus, Poole, United Kindgom, BH12 5BB \\ \{dbiggins, dholley\}@bournemouth.ac.uk \\ George Evangelinos \\ Anglia Ruskin University, Faculty of Health Social Care and Education, \\ East Road, Cambridge, United Kingdom, CB1 1PT \\ george.evangelinos@anglia.ac.uk \\ Marketa Zezulkova \\ Charles University, Insitute of Communication Studies \& Journalism \\ Smetanovo nab. 6, Prague, Czech Republic, 11000 \\ marketa.zezulkova@fsv.cuni.cz
}

\begin{abstract}
The paper explores and compares digital competence (DigComp) framework, published by EU in 2013 and updated in 2016, with digital capabilities (DigCap) framework introduced within the UK higher and further education context in 2009 and updated in 2015. The similarities found between the updated versions are in the increased focus on data in the context of privacy and overall literacy, as well as in the inclusion of wellbeing into the key areas. The main difference between the digital competence and capabilities frameworks is in the DigComp's neglect of life-long learning and selfdevelopment. The paper further discusses the frameworks, their similarities and differences, through a single UK institution case study of a technology enhanced learning toolkit for HE. It then concludes by arguing for a humancentered approach to digital competence and capability frameworks, in which learning, self-development and wellbeing should play a vital role.
\end{abstract}

Keywords: competence, capability, framework, toolkit, learning, wellbeing

\section{Introduction}

Despite the number of efforts in promoting and developing digital competence across varying social spheres such as education, health and policy, the study Measuring Digital Skills across the EU (2014) found that $47 \%$ of the EU population has insufficient digital skills, whilst $23 \%$ has none at all, as well as that $39 \%$ of the EU workforce has insufficient digital skills with $14 \%$ having no digital skills, and lastly $64 \%$ of disadvantaged people (aged 55-74, low educated, or unemployed) have an 
insufficient level of digital skills and 38\% have no digital skills at all [1]. The study adds that information and communication skills are higher than content creation and problem-solving skills among the EU population. This represents a key challenge for institutions educating young adults who seem technologically competent but at the same time might have a narrow knowledge and set of skills connected to specific platforms (e.g. social networks) and technology (e.g. mobile phones) [2a and b].

It however is not digital competence or capability per se that is important, but instead the inclusive and effective life-long learning and enabling that it embodies. Education of all levels is preoccupied with complex literacy and student's ability to navigate self-learning for continuous development [3]. Digital competence and capability therefore plays, or should play, an essential role in both enhancing immediate, and enabling life-long, learning. Recognising this, EU and distinct local organisations - such as JISC in the UK - have developed and acknowledged a number of digital competence and literacies frameworks for the purpose of encouraging and underpinning various educational and other initiatives. This paper reviews the frameworks, positions them within the HE context and explores their practical implications through a single UK institution case study of a technology enhanced learning toolkit.

\section{EU-Commissioned Digital Competence Frameworks}

The European Parliament and the Council published recommendations on key competences for lifelong learning that included digital competence in 2006, whilst defining competence as 'a combination of knowledge, skills and attitudes' and clarifying that key competences are those 'which all individuals need for personal fulfilment and development, active citizenship, social inclusion and employment' [4]. This life-long learning reference framework approaches digital competence as a confident, informed, critical, reflective, responsible, ethical, and legal use of Information Society Technology (IST) - its tools and complex information - for personal, cultural, social, creative, innovative, and/or professional purposes. EU established here that digital competence penetrates all aspects of life at all stages, but there was no strategic framework in place until Europe 2020 and its Digital Agenda (2010) made of seven pillars with one being 'promoting digital literacy, skills and inclusion' [5].

Following the Agenda, the Digital Competence (DigComp) project was commissioned by the EU DG for Education and Culture in 2011, leading to the publishing of the first DigComp framework two years later [6]. The Table 1 below summarises the core areas of the digital competence original framework from 2013, as well as its second draft of which the final version is expected to be published in May 2016. 


\section{Information}

Browsing, searching and filtering

information

Evaluation information

Storing and retrieving information

\section{Communication}

Interacting through technologies

Sharing information and content

Engaging in online citizenship

Collaborating through digital channels

\section{Netiquette}

Managing digital identity

\section{Content Creation}

Developing content

Integrating and re-elaborating

Copyrights and licences

Programming

\section{Safety}

Protecting devices

Protecting data

Protecting health

\section{Problem Solving}

Solving technical problems Identifying needs and technological responses Innovating and creatively using technology Identifying digital competence gaps

\section{Information}

Browsing, searching and filtering information

Evaluation information

Storing and retrieving information

\section{Communication}

Interacting through technologies

Sharing information and content through digital technologies

Engaging in citizenship through digital technologies

Collaborating through digital technologies Netiquette

Managing digital identity

\section{Content Creation}

Developing content

Integrating and re-elaborating content

Copyrights and licences

Programming

\section{Safety}

Protecting devices

Protecting personal data and privacy

Protecting health and well-being

Protecting the environment

\section{Problem Solving}

Solving technical problems

Identifying needs and technological responses

Creatively using digital technology

Identifying digital competence gaps

Figure 1 Digital competence framework 1.0 and its second updated draft

The proposed changes, firstly, put more emphasis on 'digital technologies', and secondly, clarify and extend the safety area. Although the revisions are not yet definitive, safety will probably undergo the most significant changes, reflecting not only the EU's but also the general public's increased concern about personal data protection and overall privacy. The seemingly less significant amendment is the inclusion of 'well-being', but we would argue otherwise. Although the decision might be underpinned mainly by EU health and well-being agenda penetrating a number 
frameworks developed under distinct strategies (e.g. EU Youth Strategy [7]), it returns digital competence to its more complex and varied role in one's life as initially recognised by The European Parliament and the Council in 2006. Moreover, wellbeing has also been recently added to the six elements of digital capability [8] developed by JISC (Joint Information Systems Committee), a UK-based non-profit organisation providing frameworks and resources for strategic development of digital literacies within the higher and further education sector. The following section will further discuss the digital capability framework and compare it with DigComp.

\section{Digital Capabilities Framework in the UK HE and FE}

Beetham and McGill led the JISC's Digital Capabilities (here referred to as DigCap) frameworks project in 2015, within which they reviewed over sixty frameworks and to them relevant websites and publications, while at the same time interviewed dozens experts based in HE and the relevant industry spheres [8]. The research found that there was a high awareness of the original seven elements of digital literacy published by JISC in 2009 [9], which allowed the research participants to provide informed insights and recommendations. They for example suggested that 'different areas visibly overlap' and thus 'described a 'venn diagram' or 'flower with overlapping

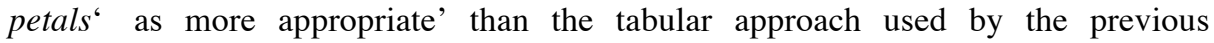
framework [8] or currently by EU's DigComp. On this ground, a new diagram visualising the updated framework has been developed (see Figure 2 below).

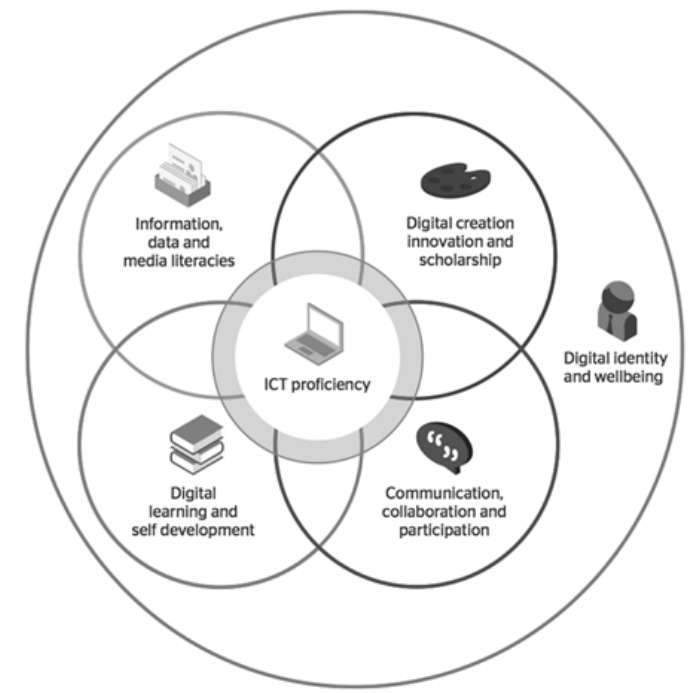

Figure 2 Digital capabilities framework and its six elements updated in 2015

When comparing the new DigCap framework with the previous seven elements of digital capabilities, the information and media literacies have been brought together and at the same time extended with data literacy. JISC's DigCap and EU's DigComp 
frameworks therefore agree on the increased importance of 'data'. However, whereas EU focuses on protecting personal data and privacy while leaving 'literacies' to other frameworks (e.g. Study on Assessment Criteria for Media Literacy Levels [10]), JISC acknowledges more explicitly their overlap.

DigCap 2009 and 2015 as well as DigComp 2013 and 2016 frameworks all stress the significance of digital creation, innovation, communication, collaboration, participation or engagement, and digital identity. In addition to these and as mentioned earlier, the latest versions of the frameworks both added 'wellbeing'. DigCap justified this, on one hand, by the research finding that 'digital practices could be a source of stress and concern' among teachers (e.g. workload) and students (e.g. cyberbullying and time management), and on the other hand, by stating that '[e]veryone can suffer if digital technologies are used without attention to human and environmental health, and without considering whether digital practices are fully inclusive and equitable' [8]. Whereas the first argument is grounded in Beetham and McGill's primary research, the second is fully consistent with EU Digital Agenda's aim to build 'inclusive, equitable and sustainable European information society' [11] as well as with other EU frameworks (e.g. Education 2030: Incheon Declaration and Framework for Action towards inclusive and equitable quality education and lifelong learning for all [12]).

The foremost striking difference between DigComp and DigCap lays in the area of scholarship, learning and self-development. Although one could argue that this is due to DigCap being developed specifically for education sector, it seems equally reasonable for DigComp to include digital learning and self-development, especially since the EU's concept of digital competence originated in its life-long learning frameworks. Among other JISC's work, Learning in a Digital Age [13] could be of interest to EU's DigComp as it identified key areas of educational activity where innovation was crucial for lifelong learning to flourish: curriculum design and delivery, assessment, and support for learners.

Additionally, current work is being undertaken with the UK skills sector looking at engaging 'digital students', learners undertaking apprenticeships; offenders; learners in the Further Education sector [14]. Patterns are starting to emerge: regarding access to technology, fast Wi-Fi with good connectivity and the availability of a PC, laptop or tablet at the course centre are identified as the most important aspects of access to technology. Thus the UK specific work very much reflects the wider EU picture of complexity with consistent issues around access to technology, contributing to the digital divide. Lifelong learning and self-development remain challenges that society struggles with, best practice shows that we need to engage our stakeholders more widely to meet this challenge. Bournemouth University (BU) is an institution that prides itself on access; all students have the opportunity to undertake a work based placement; thus getting staff to model self-development and lifelong learning and to engage students with a wider digital agenda is essential. The following section will use the case of Bournemouth University to discuss DigComp and DigCap frameworks further. 


\section{Technology Enhanced Learning and Self-Development: Case of BU Digital Toolkit}

BU's digital toolkit, developed by the Centre for Excellence in Learning (CEL), will serve here as a case study that helps to illustrate abstract ideas through examples of real situations [15]. Case study approach is popular in educational research [16] as it allows to set a phenomenon such digital competence and capability learning within its context [15]; here being higher and further education in the UK, and by extension EU.

The mission of CEL is to make a significant contribution to strategy of fusing education, professional practice and research to enhance student learning experience across the University. A major theme is technology enhanced learning (TEL). This theme harness available technology to develop the competencies and confidence of staff and to engage and enthuse students in their learning. As Heppell (2016) argues, 'one significant impact of new technologies in education has been to give teachers and learners a voice through the many "bottom up" channels' [17]. Although TEL Tools have been in use for many years, their uncoordinated growth meant that many, sometimes duplicate, tools were being used and support was sporadic.

The TEL Toolkit was envisioned as a way of bringing together these disparate resources in one place so that staff, students, partner institutions and the wider academic community would know where to go for publicly accessible TEL information [18]. Support for the Toolkit is provided by Learning Technologists and IT, ensuring it is relevant and contemporary. Students interface with the Toolkit via the practice of lecturers and independently via exploration of the website, experiences that act to raise student expectations of the use of TEL.

An important aspect of the Toolkit is the six learning pedagogies it incorporates. The first four - blended learning, feedback and feedforward, flipped classroom, and assessment - are relevant to EU's educational frameworks and JISC's DigCap, whereas the remaining two - collaboration \& co-creation and engagement - are directly aligned with both DigCap and DigComp. For each area, there is an explanation of why the pedagogy is important to teaching and learning, how staff can use the approach and the TEL tools available to develop their practice.

The TEL Toolkit is supported by an online questionnaire that enables staff to selfassess their confidence in tools and their broader digital literacy for the areas Figures 1 and 2. The rationale for the questionnaire is two fold. First, staff gain a better understanding of their own digital skills and identify areas for self-development through personalised support which links to their well-being. Secondly, CEL uses the information to make informed decisions about how and where to focus resources.

The Toolkit has been in operation for 5 months and has been favourable received by staff. There have been 1,750 sessions to the Toolkit and 8,831 page views. Each week, roughly $40 \%$ of access originates from outside the University. Competitions and social media have been used to promote staff interest and engagement. A working group has been created to continue to develop and expand the Toolkit and also to manage the feedback from staff.

The dual forces of technology-capable staff and heightened student expectations are driving TEL developments at BU and together these will enhance the student experience. 


\section{Discussion and Conclusion}

Through comparing the original and updated versions of digital competence and digital capabilities frameworks, the paper discovered parallel changes in the field of data privacy and data literacy as well as in the emphasis on wellbeing, whereas learning and self-development have been for now omitted by the EU's DigComp original and draft frameworks. Using BU's TEL digital toolkit as a case study, the paper illustrated how technological tools and human learning, self-development and wellbeing must go hand in hand, rather than being seen as separate phenomena, when discussing and applying digital competence and capabilities frameworks.

The close relationship between capability and wellbeing is possible to observe, for instance, in Alkire's [19] work that uses Sen's capability framework for the measurement of wellbeing. It can be difficult to establish a benchmark for measurement of digital competence and capabilities as the base level keeps moving up as new tools and skills become available and the levels of expected knowledge keep increasing. Even though Alkire focuses on public policy, there potentially is a space for measuring the effectiveness of an institutional TEL toolkit in a similar way. A research exploring TEL toolkit effectiveness, possibly in the context of wellbeing, is needed here.

A welcomed and positive change is the human-centered approach to digital competence and capability frameworks constructing 'human lives in terms of possibilities rather than deficits' [20] that penetrates a growing volume of recent research and practice in technology enhanced learning. If TEL is such a key area of learning and self-development, the HE and FE institutions should investigate whether it is feasible to make TEL compulsory so that TEL moves from an optional to a mandatory element of unit delivery. As the case study briefly highlighted, the ways in which TEL can rise in importance within an institution is through organisational leadership, a strategy that identifies the importance of TEL, support for staff and an embedding of the TEL philosophy in working practices such as objective setting and feedback gathering. Key to success however lays here in the human-centred approach priroritising staff and students" immediate and lifelong wellbeing rather than the mere use of digital tools.

\section{References}

1. European Commission: Measuring Digital Skills across the EU: EU wide indicators of Digital Competence (2014)

2a. Evangelinos, G., and Holley, D., 2014.(a) A Qualitative Exploration of the EU Digital Competence (DIGCOMP) Framework: A Case Study Within Healthcare Education. In: G. Vincenti, A. Bucciero and C. Vaz de Carvalho, eds., E-Learning, E-Education, and Online-Training (ELEOT) First International Conference, Lecture Notes of the Institute for Computer Sciences, Social Informatics and Telecommunications Engineering. Cham: Springer International Publishing, pp.85-92 (2014). doi: 10.1007/978-3-31913293-8. 
2b. Evangelinos, G., and Holley, D., 2015.(b) A Qualitative Exploration of the DIGCOMP Digital Competence Framework: Attitudes of students, academics and administrative staff in the health faculty of a UK HEI. EAI Endorsed Transactions on e-Learning, 2(6), p.e1. doi: 10.4108/el.2.6.e1.

3. Zezulkova, M.: Media learning in primary school classroom: Following teachers' beliefs and children's interests. In: Kotilainen, S., and Kupiainen, R., eds. Reflections on Media Education Futures, pp. 159-169 (2015)

4. The European Parliament and the Council of the European Union: Recommendation of the European Parliament and of the Council of 18 December 2006 on key competences for lifelong learning (2006)

5. European Commission: Digital Single Market Europe 2020 strategy https://ec.europa.eu/digital-single-market/en/europe-2020-strategy

6. European Commission: DIGCOMP: A Framework for Developing and Understanding Digital Competence in Europe (2013)

7. European Commission: Youth Strategy on Health and Wellbeing http://ec.europa.eu/youth/policy/youth_strategy/health_wellbeing_en.htm

8. Beetham, H.: Revisiting digital capability for 2015 (2015) http://digitalcapability.JISCinvolve.org/wp/2015/06/11/revisiting-digitalcapability-for-2015/

9. Beetham, H., McGill, L., and Littlejohn, A.: Thriving in the 21st century: Learning Literacies for the Digital Age (LLiDA project) (2009)

10. Celot, P.: Study on Assessment Criteria for Media Literacy Levels (2009) http://ec.europa.eu/culture/library/studies/literacy-criteria-report en.pdf

11. Mansell, R.: Here comes the revolution - the European Digital Agenda. In Donders, K., Pauwels, C., and Loisen, J., eds. The Palgrave Handbook of European Media Policy. Basingstoke: Palgrave Macmillan, pp. 202-217 (2014)

12. European Commission: Education 2030: Incheon Declaration and Framework for Action towards inclusive and equitable quality education and lifelong learning for all (2015)

13. JISC: Learning in a Digital Age Extending higher education opportunities for lifelong learning (2011)

14. Pepler, G., and Jeans, N.: Summary of Jisc Digital Student Skills Sector study: preliminary review of the Learner Focus Groups (2016)

15. Yin, R.K.: Case Study Research: Design and Methods. Thousands Oak: Sage. Quin (2009)

16. Quinn, R. E.: Building the Bridge As You Walk On It: A Guide For Leading Change. San Francisco: Jossey-Bass (2004)

17. Heppell, S.: From Digital Literacy to Capability: Critical review (2016)

18. Bournemouth University: The TEL Toolkit https://www1.bournemouth.ac.uk/about/centre-excellence-learning/tel-toolkit

19. Alkier, S.: The Capability Approach and Well-Being Measurement for Public Policy (2015) http://www.ophi.org.uk/wp-content/uploads/OPHIWP094.pdf

20. McDougall, J., Readman, M., and Wilkinson, P.: From Digital Literacy to Digital Capability http://www.cemp.ac.uk/downloads/From\%20Digital\%20Literacy\%20to\%20Ca pability\%20-\%20Project\%20Report.pdf 